Article

\title{
Synthesis and Characterisation of Linear and Towards Cyclic Diferrocenes with Alkynyl Spacers
}

\author{
Lucy E. Wilson, Xueying Jian $₫$, Andrew J. P. White and Nicholas J. Long * \\ Department of Chemistry, Imperial College London, South Kensington, London SW7 2AZ, UK; \\ 1.wilson13@imperial.ac.uk (L.E.W.); xueying.jian13@imperial.ac.uk (X.J.); a.white@imperial.ac.uk (A.J.P.W.) \\ * Correspondence: n.long@imperial.ac.uk; Tel.: +44-207-594-5781
}

Received: 14 August 2018; Accepted: 7 September 2018; Published: 11 September 2018

\begin{abstract}
Ferrocenediyl systems offer a motif that incorporates multiple functionality and redox-active centers, enabling these units to be used as molecular scaffolds in linear and cyclic compounds. Herein, we discuss a new modular methodology for the synthesis and incorporation of ferrocenediyl motifs within extended conjugated systems. We have synthesized a family of compounds featuring ferrocenediyl-ethynyl units with various para-substituted aromatic linkages. Extended linear, open-chain species have been isolated and understanding towards the analogous cyclic compounds gained. The new compounds have been probed using NMR, mass spectrometry, cyclic voltammetry and X-ray crystallography to gain further understanding of their structural and electronic properties.
\end{abstract}

Keywords: ferrocene; metal-alkynes; cyclic voltammetry

\section{Introduction}

The stability and redox activity of ferrocene has made it an attractive structural component and lead to the incorporation of the motif into many organometallic structures. Ferrocene units can also supply structural control and flexibility [1]. These are contributing factors that have led to its utilization in many applications including molecular wires [2-4], switches [5] and sensors [6].

In recent years, high density ferrocene-containing structures have become an important sub-section of ferrocene chemistry. Preliminary contributions were in the form of star and dendrimeric structures $[7,8]$. Such systems have now been developed to display remarkable electronic properties including exceptionally fast electron exchange properties and use in ion sensing $[9,10]$.

Recently, there has been a drive to incorporate ferrocene motifs within macrocyclic structures. These systems offer the potential to study interference effects, redox behavior and conductance. Cyclic structures have been developed that contain closely bound ferrocene units and those which are separated by linker groups. Within these systems, phenyl linker groups have been used with both the ortho and meta substitution patterns but a para derivative has not yet been reported [11-13].

In our group, we have designed several macrocyclic structures which contain para-substituted phenyl rings connected to two ferrocene units. The paper discusses the progression in synthesizing components of multi-ferrocene containing macrocycles and the study of the linker groups between them, alongside their physical and electrochemical properties, and illustrates the difficulties in moving towards fully cyclic structures. 


\section{Results}

\subsection{Synthesis and Characterisation}

The designed route to the para-substituted open chained diferrocenediyl compounds is displayed in Figure 1. Each bridged diferrocenediyl species was synthesized through a Sonogashira coupling of 1,1'-diiodoferrocene with the arene linking units terminated with ethynyl ligands utilizing the widely reported $\operatorname{Pd}\left(\mathrm{P}^{t} \mathrm{Bu}_{3}\right)_{2}$ catalyst [14]. The linker groups were chosen due to their potential for $\pi$-stacking between the arene rings and their facile electronic communication, as noted in our previous work $[15,16]$. Compound $\mathbf{2}$ has an increased length in comparison to compound $\mathbf{1}$ which is expected to alter the communication between the ferrocene centers while compound 3 offers the potential for increased solubility.

The desired compounds were achieved as the most prevalent products from the respective reactions by using an excess of 1,1'-diiodoferrocene compared to the arene linker to reduce the potential for polymerization products. Compound 1 was synthesized in reasonable yields $(43 \%)$ by a Sonogashira coupling of 1,1'-diiodoferrocene with the difunctionalised arene, and utilizing the $\operatorname{Pd}(0)$ catalyst $\operatorname{Pd}\left({ }^{t} \mathrm{Bu}_{3}\right)_{2}$, followed by purification via column chromatography on silica gel. The same procedure was utilized to synthesize compounds 2 and 3 in $27 \%$ and $60 \%$ yields respectively. All products were characterized by NMR spectroscopy, mass spectrometry, elemental analysis and in the case of 1, X-ray crystallography. NMR experiments gave largely expected data in terms of chemical shifts and coupling constants (see experimental section for details) and the spectra of the ${ }^{1} \mathrm{H} N M R,{ }^{13} \mathrm{C}\{1 \mathrm{H}\} \mathrm{NMR}, \mathrm{COSY}$ and HSQC experiments are detailed in the Supplementary Information (Figures $\mathrm{S} 1-\mathrm{S} 3$ respectively).
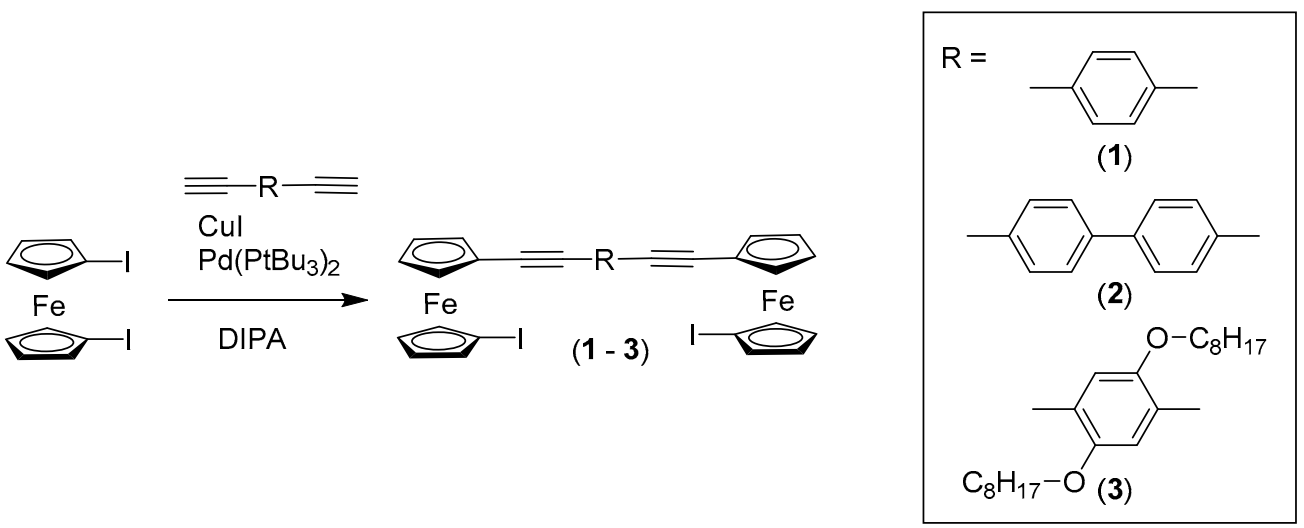

Figure 1. Reaction scheme to form open-chain diferrocenediyl alkynyl systems.

Cyclisation of compounds 1 and 3 (reactions involving compound $\mathbf{2}$ were too insoluble to give meaningful data) was then attempted with the second bridge to be inserted being the same bridging arene ligand already located within the compound. Reactions were carried out under high dilution conditions in DIPA and THF, again under Sonagashira coupling conditions. Unfortunately, no cyclic products could be identified in any of these products however, an array of new linear diferrocenediyl systems were formed (Figure 2). For $\mathbf{1}$ and $\mathbf{3}$, the main products from the reaction were the open-chained systems (compounds 4 and 5 ). Compound 4 was purified by column chromatography and identified by NMR spectrometry and mass spectrometry. In the ${ }^{1} \mathrm{H}$ NMR spectrum (Figure S4), the multiplets at $\delta 7.40$ to $7.30 \mathrm{ppm}$ correspond to the eight $\mathrm{H}$ atoms on the two phenyl rings. The pseudo triplets at $\delta 4.49,4.46,4.28$ and $4.30 \mathrm{ppm}$ are all signals due to the iodoferrocene unit while the peaks at $\delta 4.55$ and $4.35-4.33 \mathrm{ppm}$ are due to the other ferrocene unit. Both these peaks are due to the overlaying of two pseudo triplets due to the asymmetry around this ferrocene unit. Furthermore, the singlet at $\delta 3.16 \mathrm{ppm}$ corresponds to the proton on the terminal alkyne. Mass spectrometry showed a peak at $m / z 743.98$ (expected $m / z$ 743.97). Compound 5 was more difficult to purify but was 
identified via mass spectrometry, with three overlapping product bands being observed on the column that could not be fully separated.

The unfortunate lack of cyclisation reactions under these conditions could be due to a high energy cyclisation barrier, steric strain and/or the conformation of the starting ferrocenediyl unit making cyclisation reaction difficult. Changing some of the reaction conditions could improve the result and lead to cyclisation. For example, the use of even higher dilution to further reduce the chance of the formation of linear of polymeric by-products; or a decrease in reaction temperature to limit the movement and conformational freedom of the molecule.

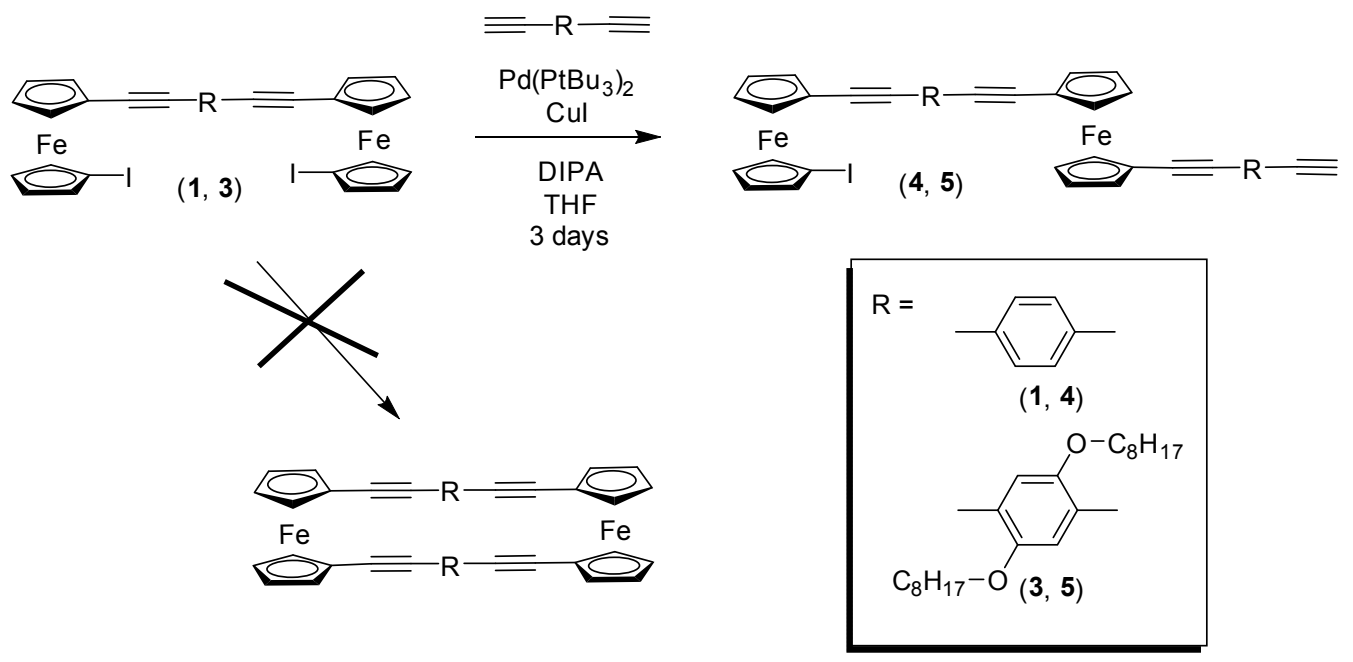

Figure 2. Reaction scheme to form open, linear diferrocenediyl, and potentially closed macrocyclic, systems.

\subsection{X-ray Crystallography}

The structure of $\mathbf{1}$ (Figure 3) was determined by single-crystal X-ray diffraction of crystals grown by solvent layering of $n$-hexane $/ \mathrm{CH}_{2} \mathrm{Cl}_{2}$. Selected bond lengths are shown in Table 1 . The structure shows a trans-conformation of the ferrocene units with the iodine atoms pointing into the structure. The structure of $\mathbf{1}$ was found to sit across a center of symmetry at the middle of the $\mathrm{C}_{6} \mathrm{H}_{4}$ ring.

Table 1. Selected bond lengths and angles for compound $\mathbf{1 .}$

\begin{tabular}{cccc}
\hline \multicolumn{2}{c}{ Selected Bond Lengths $(\mathbf{A})$} & \multicolumn{2}{c}{ Selected Bond Angles $\mathbf{(}^{\circ}$ ) } \\
\hline $\mathrm{C} 1-\mathrm{C} 11$ & $1.436(5)$ & $\mathrm{C} 1-\mathrm{C} 11-\mathrm{C} 12$ & $178.5(4)$ \\
$\mathrm{C} 11-\mathrm{C} 12$ & $1.185(5)$ & $\mathrm{C} 11-\mathrm{C} 12-\mathrm{C} 13$ & $178.4(4)$ \\
$\mathrm{C} 12-\mathrm{C} 13$ & $1.441(5)$ & $\mathrm{C} 11-\mathrm{C} 5$ (cent) $\cdots \mathrm{C}_{\text {(cent) }}$ & $\mathrm{ca} .92 .1$ \\
$\mathrm{C} 6-\mathrm{I} 1$ & $2.081(4)$ & $\mathrm{I}-\mathrm{C} 5$ (cent) $\cdots \mathrm{C}_{\text {(cent) }}$ & $\mathrm{ca} .94 .0$ \\
Fe1-Fe1 intra & $13.8626(14)$ & $\mathrm{C} 12-\mathrm{C} 13-\mathrm{C}_{6} \mathrm{H}_{4}$ (cent) & $\mathrm{ca} .179 .6$ \\
\hline
\end{tabular}

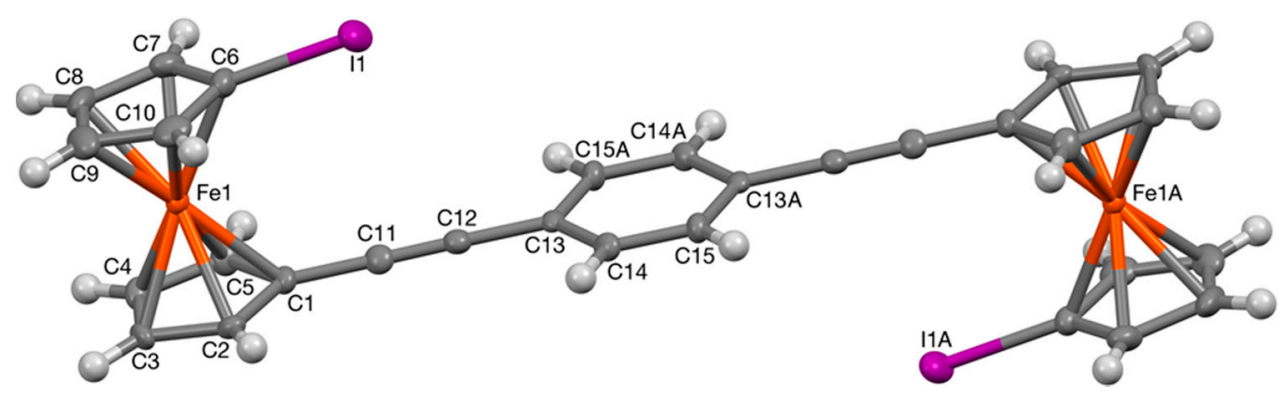

Figure 3. Molecular structure of 1, showing atom-labelling scheme. 


\subsection{Electrochemistry}

The electrochemical properties of complexes 1, 2 and $\mathbf{3}$ were studied to probe the communication through the bridging units. Cyclic voltammetry $(\mathrm{CV})$ and differential potential voltammetry (DPV) experiments were run in a $0.1 \mathrm{M}$ solution of $\left[\left({ }^{n} \mathrm{Bu}\right)_{4} \mathrm{~N}\right] \mathrm{PF}_{6}$ in DCM. Relevant data are summarized in Table 2 and displayed in Figure 4.

Table 2. Electrochemical data for cyclic voltammetry experiments of compounds 1, 2 and 3.

\begin{tabular}{cccc}
\hline Compound & $\boldsymbol{E}_{\mathbf{1 / 2}}(\mathbf{m V})$ & $\Delta E(\mathbf{m V})$ & $\boldsymbol{i}_{\boldsymbol{p a}} / \boldsymbol{i}_{\boldsymbol{p c}}$ \\
\hline $\mathbf{1}$ & 0.257 & 0.079 & 0.85 \\
$\mathbf{2}$ & 0.239 & 0.059 & 0.83 \\
$\mathbf{3}$ & 0.259 & 0.090 & 0.92 \\
\hline
\end{tabular}

Conditions: Scan rate $0.1 \mathrm{~V} \cdot \mathrm{s}^{-1}$. Working electrode: Glassy carbon, Counter and reference electrodes: Pt wire. All potentials reported in $\mathrm{V}$ relative to an internal $\left[\mathrm{Cp}_{2} \mathrm{Fe}\right] /\left[\mathrm{Cp}_{2} \mathrm{Fe}\right]^{+}$reference and corrected for $i$ Rs. Measured against an internal $\left[\mathrm{Cp}_{2}^{*} \mathrm{Fe}\right] /\left[\mathrm{Cp}_{2}{ }_{2} \mathrm{Fe}\right]^{+}$reference $\left(-0.495 \mathrm{~V}\right.$ vs. $\left[\mathrm{Cp}_{2} \mathrm{Fe}\right] /\left[\mathrm{Cp}_{2} \mathrm{Fe}\right]^{+}$in our system).

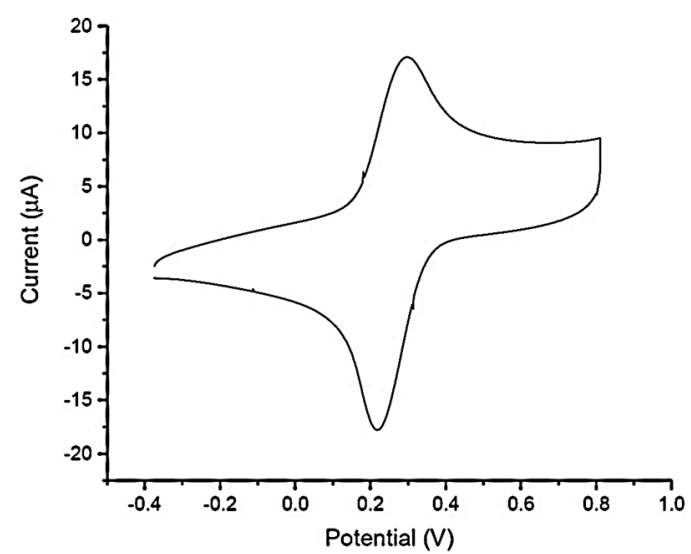

(a)

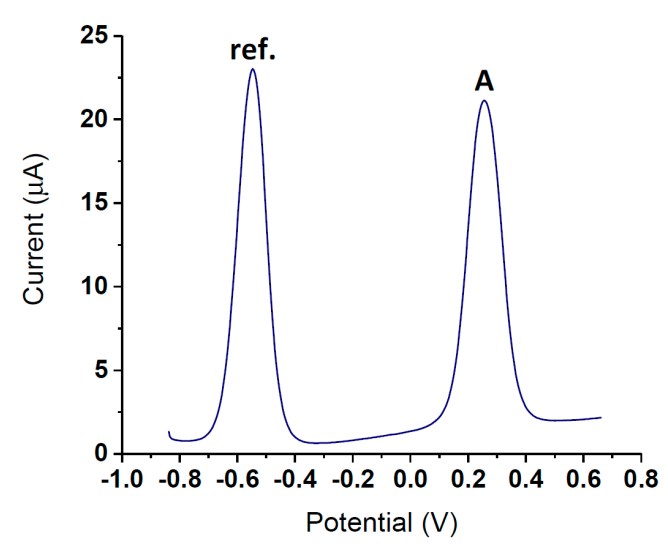

(b)

Figure 4. Solution electrochemistry for $\mathbf{1}$ (details for $\mathbf{2}$ and $\mathbf{3}$ are very similar). Left (a): Cyclic voltammogram of $\mathbf{1}$. Right (b): Differential pulse voltammogram showing peak of $\mathbf{1}$ with decamethylferrocene as reference.

Compounds 1, 2 and 3 display a reversible redox event at an $E_{1 / 2}$ close to $260 \mathrm{mV}$, with the values of 1 and 3 being indistinguishable and those for 2 being at a slightly lower potential. This could be due less stabilization of the charges on the ferrocenes across the biphenyl bridge of 2 in comparison to 1 and 3.

With $i_{p} \propto \mathrm{v}_{\mathrm{s}}{ }^{1 / 2}$, this suggests that a purely diffusion based process is observed for all these compounds. These systems also show an $i_{p a} / i_{p c} \approx 1$, suggestive of a reversible system i.e., a value of $\Delta E \approx 59 \mathrm{mV}$ is expected for a reversible one-electron exchange. This value was found for compound $\mathbf{2}$ but larger values were found for $\mathbf{1}$ and $\mathbf{3}$. This could be due to broadening of the peaks due to a low level of communication between the ferrocene centers over the bridge. This argument is further strengthened by an increase in the FWHM value of $\mathbf{1}$ and $\mathbf{3}$ in the DPV spectra (Figure 4 right and Figures S5-S7).

The low levels of communication in all these systems is expected to be due to the rotation of the bridging motifs between the metals centers. This is further decreased in $\mathbf{2}$ due to increased rotation of the two (as opposed to single) rings [17].

In conclusion, within this paper we have reported the synthesis of several new linear, open-chain conjugated ferrocenediyl molecules. We have described a modular, step-wise methodology that also has the potential to lead to a range of cyclic, ferrocenediyl systems featuring bridging diethynyl-arene units. The Sonagashira-coupling synthetic methodology displays good yields and versatility in 
the products that can be produced. The compounds have been probed through crystallography, electrochemistry and NMR analysis. The synthetic methodology will enable the synthesis of a wider range and more complex ferrocene-containing molecules, moving towards fully macrocyclic compounds under optimal reaction conditions.

\section{Materials and Methods}

\subsection{Experimental}

General: All reactions were performed using standard air sensitive chemistry and Schlenk line techniques under an atmosphere of nitrogen. No special precautions were taken to exclude air during the work-up. Solvents used in reactions were collected from solvent towers sparged with nitrogen and dried with $3 \AA$ molecular sieves, apart from diisopropylamine (DIPA), which was distilled onto activated $3 \AA$ A molecular sieves. 1,1'-Diiodoferrocene [18], 4,4'-diethynyl-1,1'-biphenyl [19] and 2,5-diethynyl-1,4-dioctyloxybenzene [20] were prepared via literature procedures from commercially available starting materials. All other compounds were purchased from commercial suppliers and used without further purification.

${ }^{1} \mathrm{H}$ and ${ }^{13} \mathrm{C}\left\{{ }^{1} \mathrm{H}\right\}$ NMR spectra were recorded on a Bruker Avance $400 \mathrm{MHz}$ spectrometer (Bruker UK, Coventry, UK) and referenced to the residual solvent peaks of $\mathrm{CDCl}_{3}$ at 7.26 and $77.16 \mathrm{ppm}$ respectively. ${ }^{13} \mathrm{C}\left\{{ }^{1} \mathrm{H}\right\}$ spectra were fully assigned where possible using $2 \mathrm{D}$ correlation spectroscopy. Coupling constants are measured in Hz. Mass spectrometry analyses were conducted by Lisa Haigh of the Mass Spectrometry Service, Imperial College London. Microanalyses were carried out at the Science Centre, London Metropolitan University, by Stephen Boyer using a Thermo Scientific (Carlo Erba, Milan, Italy) Flash 2000 Organic Elemental Analyser (Thermo Scientific, Waltham, MA, USA), configured for \%CHN. Cyclic voltammograms were recorded under an atmosphere of argon in $\mathrm{CH}_{2} \mathrm{Cl}_{2} / 0.1\left[{ }^{n} \mathrm{Bu}_{4}\right]\left[\mathrm{PF}_{6}\right]$ on a Gamry reference $600^{\mathrm{TM}}$ (Gamry Instruments, Warminster, PA, USA) with a glassy carbon disc as working electrode (diameter $=2.5 \mathrm{~mm}$ ), and Pt-wire as reference and counter electrodes. Analyte solutions were between 0.1 and $1 \mathrm{mM}$. Potentials are reported relative to $\left[\mathrm{Cp}_{2} \mathrm{Fe}\right]^{+} /\left[\mathrm{Cp}{ }_{2} \mathrm{Fe}\right]$, measured against internal $\left[\mathrm{Cp}_{2}{ }_{2} \mathrm{Fe}\right]^{+} /\left[\mathrm{Cp}^{*}{ }_{2} \mathrm{Fe}\right]$ references.

\subsubsection{Synthesis of Compound 1}

A solution of 1,1'-diiodoferrocene $(6.00 \mathrm{~g}, 13.73 \mathrm{mmol})$ in dry DIPA (30 mL) was added to an oven-dried Schlenk flask and was degassed under $\mathrm{N}_{2}$ for $10 \mathrm{~min}$. 1,4-Diethynylbenzene (150 mg, $1.29 \mathrm{mmol})$ and $\mathrm{CuI}(15 \mathrm{mg}, 0.079 \mathrm{mmol})$ were added to the solution against the flow of $\mathrm{N}_{2}$ and degassed for a further $10 \mathrm{~min} . \mathrm{Pd}\left(\mathrm{P}^{t} \mathrm{Bu}_{3}\right)_{2}(40 \mathrm{mg}, 0.78 \mathrm{mmol})$ were added to the solution against the flow of $\mathrm{N}_{2}$ and the reaction mixture was stirred overnight at room temperature covered with aluminum foil. The solvent was removed and the crude product was purified by silica gel column chromatography, eluted with $n$-hexane $/ \mathrm{CH}_{2} \mathrm{Cl}_{2}(1: 0 \rightarrow 0: 1 \mathrm{v} / v)$ to gain the product as a red-orange powder $(381 \mathrm{mg}, 43 \%)$.

${ }^{1} \mathrm{H} \mathrm{NMR}\left(400 \mathrm{MHz}, \mathrm{CDCl}_{3}\right): \delta(\mathrm{ppm}) 7.49(\mathrm{~s}, 4 \mathrm{H},-\mathrm{Ph}-), 4.51\left(\mathrm{t},{ }^{3} \mathrm{JHH}_{\mathrm{HH}}=1.9 \mathrm{~Hz}, 4 \mathrm{H}, \mathrm{Cp}-\mathrm{C}\right), 4.48(\mathrm{t}$, $\left.{ }^{3} J_{\mathrm{HH}}=1.8 \mathrm{~Hz}, 4 \mathrm{H}, \mathrm{Cp}-\mathrm{I}\right), 4.30\left(\mathrm{t},{ }^{3} \mathrm{~J}_{\mathrm{HH}}=1.9 \mathrm{~Hz}, 4 \mathrm{H}, \mathrm{Cp}-\mathrm{C}\right), 4.27\left(\mathrm{t},{ }^{3} \mathrm{~J}_{\mathrm{HH}}=1.8 \mathrm{~Hz}, 4 \mathrm{H}, \mathrm{Cp}-\mathrm{I}\right) .{ }^{13} \mathrm{C}\left\{{ }^{1} \mathrm{H}\right\}$ NMR (126 MHz, $\mathrm{CDCl}_{3}$ ): $\delta$ (ppm) 131.3, 123.1, 88.9, 86.8, 76.4, 74.1, 72.1, 70.9, 67.4, 41.2. TOF MS ES ${ }^{+}$: $m / z$ 745.8, ([M] ${ }^{+}$calc.: 745.84). Anal. Calcd. for $\mathrm{C}_{30} \mathrm{H}_{20} \mathrm{Fe}_{2} \mathrm{I}_{2}: 48.30 ; \mathrm{H}, 2.70$. Found: $\mathrm{C}, 48.41 ; \mathrm{H}, 3.00$.

\subsubsection{Synthesis of Compound 2}

A solution of $1,1^{\prime}$-diiodoferrocene $(4.38 \mathrm{~g}, 10 \mathrm{mmol})$ in dry DIPA $(25 \mathrm{~mL})$ was added to an oven-dried Schlenk tube and was degassed under $\mathrm{N}_{2}$ for $10 \mathrm{~min} .4,4^{\prime}$-Diethynyl-1,1'-biphenyl $(200 \mathrm{mg}$, $10 \mathrm{mmol}$ ) and $\mathrm{CuI}(9.5 \mathrm{mg}, 0.05 \mathrm{mmol})$ were added to the solution against the flow of $\mathrm{N}_{2}$ and degassed for a further $10 \mathrm{~min}$. $\mathrm{Pd}\left(\mathrm{P}^{t} \mathrm{Bu}_{3}\right)_{2}(77 \mathrm{mg}, 0.15 \mathrm{mmol})$ were added to the solution against the flow of $\mathrm{N}_{2}$ and the reaction mixture was stirred overnight at room temperature covered with aluminium foil. The solvent was removed and the crude product was purified by chromatography on a silica 
column, eluted with $n$-hexane $/ \mathrm{CH}_{2} \mathrm{Cl}_{2}(1: 0 \rightarrow 0: 1 v / v)$ to gain the product as an orange powder (216.4 mg, 27\%).

${ }^{1} \mathrm{H}$ NMR $\left(400 \mathrm{MHz}, \mathrm{CDCl}_{3}\right): \delta(\mathrm{ppm}) 7.61(\mathrm{~s}, 8 \mathrm{H},-\mathrm{Ph}-\mathrm{Ph}-), 4.52\left(\mathrm{t},{ }^{3} \mathrm{~J}_{\mathrm{HH}}=1.9 \mathrm{~Hz}, 4 \mathrm{H}, \mathrm{Cp}\right), 4.49(\mathrm{t}$, $\left.{ }^{3} J_{\mathrm{HH}}=1.7 \mathrm{~Hz}, 4 \mathrm{H}, \mathrm{Cp}\right), 4.31\left(\mathrm{t},{ }^{3} J_{\mathrm{HH}}=2.0 \mathrm{~Hz}, 4 \mathrm{H}, \mathrm{Cp}\right), 4.27\left(\mathrm{t},{ }^{3} J_{\mathrm{HH}}=1.8 \mathrm{~Hz}, 4 \mathrm{H}, \mathrm{Cp}\right) .{ }^{13} \mathrm{C}\left\{{ }^{1} \mathrm{H}\right\} \mathrm{NMR}$ $\left(101 \mathrm{MHz}, \mathrm{CDCl}_{3}\right.$ ): $\delta$ (ppm) 139.7, 132.0, 126.8, 123.1, 88.1, 86.8, 76.4, 74.1, 72.1, 70.9, 67.6, 41.2. TOF MS ES+: $m / z$ 821.8, ([M] $]^{+}$calc.: 821.87). Anal. Calcd. for $\mathrm{C}_{36} \mathrm{H}_{24} \mathrm{Fe}_{2} \mathrm{I}_{2}: 52.60 ; \mathrm{H}, 2.94$. Found: $\mathrm{C}, 52.59$; $\mathrm{H}, 3.07$.

\subsubsection{Synthesis of Compound 3}

A solution of 1,1'-diiodoferrocene $(2.29 \mathrm{~g}, 5.23 \mathrm{mmol})$ in dry DIPA $(15 \mathrm{~mL})$ was added to an oven-dried Schlenk tube and was degassed under $\mathrm{N}_{2}$ for $10 \mathrm{~min}$. 2,5-Diethynyl-1,4-dioctyloxybenzene (200 mg, $0.52 \mathrm{mmol}$ ) and $\mathrm{CuI}(5 \mathrm{mg}, 0.026 \mathrm{mmol})$ were added to the solution against the flow of $\mathrm{N}_{2}$ and degassed for a further $10 \mathrm{~min} . \mathrm{Pd}\left(\mathrm{P}^{t} \mathrm{Bu}_{3}\right)_{2}(40 \mathrm{mg}, 0.078 \mathrm{mmol})$ were added to the solution against the flow of $\mathrm{N}_{2}$ and the reaction mixture was stirred overnight at room temperature covered with aluminium foil. The solvent was removed and the crude product was purified by chromatography on a silica column, eluted with $n$-hexane $/ \mathrm{CH}_{2} \mathrm{Cl}_{2}(1: 0 \rightarrow 0.8: 0.2 \mathrm{v} / \mathrm{v})$ to gain the product as an red-orange solid (312 mg, 60\%).

${ }^{1} \mathrm{H} \mathrm{NMR}\left(400 \mathrm{MHz}, \mathrm{CDCl}_{3}\right): \delta(\mathrm{ppm}) 7.00(\mathrm{~s}, 2 \mathrm{H}), 4.51\left(\mathrm{t},{ }^{3} \mathrm{~J}_{\mathrm{HH}}=1.9 \mathrm{~Hz}, 4 \mathrm{H}\right), 4.49\left(\mathrm{t},{ }^{3} J_{\mathrm{HH}}=1.8 \mathrm{~Hz}\right.$, $4 \mathrm{H}), 4.28\left(\mathrm{td},{ }^{3} J_{\mathrm{HH}}=1.9,0.7 \mathrm{~Hz}, 8 \mathrm{H}\right), 4.04\left(\mathrm{t},{ }^{3} J_{\mathrm{HH}}=6.5 \mathrm{~Hz}, 4 \mathrm{H},-\mathrm{OCH}_{2}-\right), 1.95-1.83(\mathrm{~m}, 4 \mathrm{H}$, $\left.-\mathrm{OCH}_{2} \mathrm{CH}_{2}-\right), 1.62-1.25(\mathrm{~m}, 20 \mathrm{H}), 0.91\left(\mathrm{t},{ }^{3} \mathrm{~J}_{\mathrm{HH}}=7.0 \mathrm{~Hz}, 6 \mathrm{H}\right) .{ }^{13} \mathrm{C}\left\{{ }^{1} \mathrm{H}\right\}$ NMR $\left(101 \mathrm{MHz}, \mathrm{CDCl}_{3}\right)$ : $\delta(\mathrm{ppm}) 153.6,117.1,114.0,92.4,83.3,76.4,74.1,72.4,71.3,69.7,67.6,40.7,31.9,29.5,29.4,29.4,26.1$, 22.7, 14.1. TOF $\mathrm{MS} \mathrm{ES}^{+}: m / z$ 1002.08, ([M] calc.: 1002).

\subsubsection{Synthesis of Compound 4}

Compound 1 (100 mg, $0.135 \mathrm{mmol})$, 1,4-diethynylbenzene (17 mg, $0.135 \mathrm{mmol})$, CuI (0.5 mg $0.0027 \mathrm{mmol})$ and THF $(70 \mathrm{~mL})$ were combined under $\mathrm{N}_{2}$ and degassed for $10 \mathrm{~min}$. DIPA ( $\left.30 \mathrm{~mL}\right)$ was added to the solution and degassed for a further $10 \mathrm{~min} . \mathrm{Pd}\left(\mathrm{P}^{t} \mathrm{Bu}_{3}\right)_{2}(3.4 \mathrm{mg}, 0.00675 \mathrm{mmol})$ was added against a flow of $\mathrm{N}_{2}$. The reaction was stirred at room temperature for 3 days. The solvent was removed and the crude product was purified by chromatography on a silica column, eluted with $n$-hexane $/ \mathrm{CH}_{2} \mathrm{Cl}_{2}(1: 0 \rightarrow 0: 1 \mathrm{v} / \mathrm{v})$ to gain the product as an orange solid $(312 \mathrm{mg}, 60 \%)$.

${ }^{1} \mathrm{H}$ NMR $\left(400 \mathrm{MHz}, \mathrm{CDCl}_{3}\right): \delta(\mathrm{ppm}) 7.40-7.30(\mathrm{~m}, 8 \mathrm{H}, \mathrm{Ph}), 4.55\left(\mathrm{t},{ }^{3} \mathrm{~J}_{\mathrm{HH}}=4.6 \mathrm{~Hz}, 4 \mathrm{H}\right.$, $\mathrm{Cp}), 4.49\left(\mathrm{t},{ }^{3} J_{\mathrm{HH}}=4.5 \mathrm{~Hz}, 2 \mathrm{H}, \mathrm{Cp}\right), 4.46\left(\mathrm{t},{ }^{3} \mathrm{~J}_{\mathrm{HH}}=4.5 \mathrm{~Hz}, 2 \mathrm{H}, \mathrm{Cp}\right), 4.35-4.33(\mathrm{~m}, 4 \mathrm{H}, \mathrm{Cp}), 4.28(\mathrm{t}$, $\left.{ }^{3} J_{\mathrm{HH}}=4.3 \mathrm{~Hz}, 2 \mathrm{H}, \mathrm{Cp}\right), 4.3\left(\mathrm{t},{ }^{3} J_{\mathrm{HH}}=4.5 \mathrm{~Hz}, 2 \mathrm{H}, \mathrm{Cp}\right), 3.16$ (s, $1 \mathrm{H}$, ethynyl). TOF MS ES ${ }^{+}: m / z 743.98$, ([M] ${ }^{+}$calc.: 743.97$) .{ }^{13} \mathrm{C}\left\{{ }^{1} \mathrm{H}\right\} \mathrm{NMR}\left(101 \mathrm{MHz}, \mathrm{CDCl}_{3}\right): \delta$ (ppm) $132.5,132.5,132.3,132.1,131.4,131.3$, 89.6, 89.1, 89.0, 87.0, 86.8, 86.4, 83.6, 78.8, 76.5, 74.2, 73.2, 73.2, 72.3, 71.2, 71.1, 71.1, 67.6, 67.2, 66.9, 53.6, 29.9 .

\subsubsection{Synthesis of Compound 5}

Compound 2 (111 mg, $0.135 \mathrm{mmol})$, 2,5-diethynyl-1,4 dioctyloxybenzene (52 mg, $0.135 \mathrm{mmol})$, CuI (0.5 mg $0.0027 \mathrm{mmol})$ and THF $(70 \mathrm{~mL})$ were combined under $\mathrm{N}_{2}$ and degassed for $10 \mathrm{~min}$. DIPA $(30 \mathrm{~mL})$ was added to the solution and degassed for a further $10 \mathrm{~min}$. $\mathrm{Pd}\left(\mathrm{P}^{t} \mathrm{Bu}_{3}\right)_{2}(3.4 \mathrm{mg}$, $0.00675 \mathrm{mmol}$ ) was added against a flow of $\mathrm{N}_{2}$. The reaction was stirred at room temperature for 3 days. The solvent was removed and the crude product was attempted to be purified by repeated chromatography on silica or alumina columns, eluting with varying ratios of $n$-hexane $/ \mathrm{CH}_{2} \mathrm{Cl}_{2}$. Three products were identified on the columns but could not be fully separated to enable complete characterization. Evidence for the open-chained diferrocenedi-yl compound $\mathbf{5}$ was gained from mass spectrometry. TOF MS ES ${ }^{+}: m / z$ 1256.50, ([M] ${ }^{+}$calc.: 1256.45).

Supplementary Materials: The following are available online at http:/ /www.mdpi.com/2304-6740/6/3/95/s1; Figure S1: Compound 1: ${ }^{1} \mathrm{H}$ NMR, ${ }^{13} \mathrm{C}\left\{{ }^{1} \mathrm{H}\right\}$ NMR, COSY and $\mathrm{HSQC}$ in $\mathrm{CDCl}_{3}$; Figure S2: Compound 2: ${ }^{1} \mathrm{H}$ NMR, 
${ }^{13} \mathrm{C}\left\{{ }^{1} \mathrm{H}\right\}$ NMR, COSY and HSQC in $\mathrm{CDCl}_{3}$; Figure S3: Compound 3: ${ }^{1} \mathrm{H}$ NMR, ${ }^{13} \mathrm{C}\left\{{ }^{1} \mathrm{H}\right\} \mathrm{NMR}, \mathrm{COSY}$ and HSQC in $\mathrm{CDCl}_{3}$; Figure S4: Compound 4: ${ }^{1} \mathrm{H}$ NMR, ${ }^{13} \mathrm{C}\left\{{ }^{1} \mathrm{H}\right\} \mathrm{NMR}, \mathrm{COSY}$ and HSQC in $\mathrm{CDCl}_{3}$; Figure S5: Cyclic voltammetry of 1 in $0.1 \mathrm{M}\left[\left({ }^{n} \mathrm{Bu}\right)_{4} \mathrm{~N}_{\mathrm{PF}_{6}} / \mathrm{CH}_{2} \mathrm{Cl}_{2}\left(\mathrm{E}\right.\right.$ vs. [C $\left.\left.\mathrm{C}_{2} \mathrm{Fe}\right] /\left[\mathrm{Cp}_{2} \mathrm{Fe}\right]^{+}\right)$; Figure S6: Cyclic voltammetry of 2 in $0.1 \mathrm{M}\left[\left({ }^{n} \mathrm{Bu}\right)_{4} \mathrm{~N}_{\mathrm{PF}_{6}} / \mathrm{CH}_{2} \mathrm{Cl}_{2}\left(\mathrm{E}\right.\right.$ vs. $\left.\left[\mathrm{Cp}_{2} \mathrm{Fe}\right] /\left[\mathrm{Cp}_{2} \mathrm{Fe}\right]^{+}\right)$; Figure S7: Cyclic voltammetry of 3 in $0.1 \mathrm{M}$ $\left[\left({ }^{n} \mathrm{Bu}\right)_{4} \mathrm{~N}\right] \mathrm{PF}_{6} / \mathrm{CH}_{2} \mathrm{Cl}_{2}\left(\mathrm{E}\right.$ vs. $\left.\left[\mathrm{Cp}_{2} \mathrm{Fe}\right] /\left[\mathrm{Cp}_{2} \mathrm{Fe}\right]^{+}\right)$. X-ray crystallography data. References $[21,22]$ are cited in the Supplementary Materials.

Author Contributions: Conceptualization of the project, L.E.W. and N.J.L.; Methodology, L.E.W., X.J., A.J.P.W.; Validation, L.E.W., X.J., A.J.P.W., N.J.L.; Investigation, L.E.W., X.J.; Resources, N.J.L.; Writing-Original Draft Preparation, L.E.W., A.J.P.W., N.J.L.; Writing-Review \& Editing, L.E.W., A.J.P.W., N.J.L.

Funding: This research was funded by the EPSRC and Imperial College London as part of a Prize Doctoral Fellowship (L.E.W.) grant number CHCM_P70438.

Conflicts of Interest: The authors declare no conflict of interest.

\section{References}

1. Astruc, D. Why is Ferrocene so Exceptional? Eur. J. Inorg. Chem. 2017, 1, 6-29. [CrossRef]

2. Sun, Y.-Y.; Peng, Z.-L.; Hou, R.; Liang, J.-H.; Zheng, J.-F.; Zhou, X.-Y.; Zhou, X.-S.; Jin, S.; Niu, Z.-J.; Mao, B.-W. Enhancing Electron Transport in Molecular Wires by Insertion of a Ferrocene Center. Phys. Chem. Chem. Phys. 2014, 16, 2260-2267. [CrossRef] [PubMed]

3. Getty, S.A.; Engtrakul, C.; Wang, L.; Liu, R.; Ke, S.-H.; Baranger, H.-U.; Yang, W.; Fuhrer, M.S.; Sita, L.R. Near-perfect Conduction Through a Ferrocene-based Molecular Wire. Phys. Rev. B Solid State 2005, 71, 241401.1-241401.4. [CrossRef]

4. Wilson, L.E.; Hassenrück, C.; Winter, R.F.; White, A.J.P.; Albrecht, T.; Long, N.J. Functionalised Biferrocene Systems towards Molecular Electronics. Eur. J. Inorg. Chem. 2017, 2, 496-504. [CrossRef]

5. Xiao, X.; Brune, D.; He, J.; Lindsay, S.; Gorman, C.B.; Tao, N. Redox-gated electron transport in electrically wired ferrocene molecules. Chem. Phys. 2006, 326, 138-143. [CrossRef]

6. Sun, R.; Wang, L.; Yu, H.; Abdin, Z.; Chen, Y.; Huang, J.; Tong, R. Molecular Recognition and Sensing Based on Ferrocene Derivatives and Ferrocene-Based Polymers. Organometallics 2014, 33, 4560-4573. [CrossRef]

7. Diallo, A.K.; Absalon, C.; Ruiz, J.; Astruc, D. Ferrocenyl-Terminated Redox Stars: Synthesis and Electrostatic Effects in Mixed-Valence Stabilization. J. Am. Chem. Soc. 2011, 133, 629-641. [CrossRef] [PubMed]

8. Valério, C.; Fillaut, J.-L.; Ruiz, J.; Guittard, J.; Blais, J.-C.; Astruc, D. The Dendritic Effect in Molecular Recognition: Ferrocene Dendrimers and their use as Supramolecular Redox Sensors for the Recognition of Small Inorganic Anions. J. Am. Chem. Soc. 1997, 119, 2588-2589. [CrossRef]

9. Astruc, D.; Ornelas, C.; Ruiz, J. Metallocenyl Dendrimers and their Applications in Molecular Electronics, Sensing, and Catalysis. Acc. Chem. Res. 2008, 41, 841-856. [CrossRef] [PubMed]

10. Gorman, C.B.; Smith, J.C.; Hager, M.W.; Parkhurst, B.L.; Sierzputowska-Gracz, H.; Haney, C.A. Molecular Structure-property Relationships for Electron-transfer Rate Attenuation in Redox-active Core Dendrimers. J. Am. Chem. Soc. 1999, 121, 9958-9966. [CrossRef]

11. Inkpen, M.S.; Scheerer, S.; Linseis, M.; White, A.J.P.; Winter, R.F.; Albrecht, T.; Long, N.J. Oligomeric Ferrocene Rings. Nat. Chem. 2016, 8, 825-830. [CrossRef] [PubMed]

12. Hoffmann, V.; Pleux, L.; Häussinger, D.; Unke, O.T.; Prescimone, A.; Mayor, M. Deltoid versus Rhomboid: Controlling the Shape of Bis-ferrocene Macrocycles by the Bulkiness of the Substituents. Organometallics 2017, 36, 858-866. [CrossRef]

13. Wilson, L.E.; Hassenrück, C.; Winter, R.F.; White, A.J.P.; Albrecht, T.; Long, N.J. Ferrocene- and Biferrocene-Containing Macrocycles towards Single-Molecule Electronics. Angew. Chem. Int. Ed. 2017, 56, 6838-6842. [CrossRef] [PubMed]

14. Inkpen, M.S.; White, A.J.P.; Albrecht, T.; Long, N.J. Rapid Sonogashira cross-coupling of iodoferrocenes and the unexpected cyclo-oligomerization of 4-ethynylphenylthioacetate. Chem. Commun. 2013, 49, 5663-5665. [CrossRef] [PubMed]

15. Long, N.J.; Martin, A.J.; Vilar, R.; White, A.J.P.; Williams, D.J. Synthesis, Characterization, and Theoretical Studies of New Alkynylferrocene and -Biferrocene Ligands and their Platinum-containing Dimers and Oligomers. Organometallics 1999, 18, 4261-4269. [CrossRef]

16. Younus, M.; Long, N.J.; Raithby, P.R.; Lewis, J. Synthetic, Spectroscopic and Electrochemical Characterisation of Mixed-Metal Acetylide Complexes. J. Organomet. Chem. 1998, 570, 55-62. [CrossRef] 
17. Ward, M.D. Metal-metal Interactions in Binuclear Complexes Exhibiting Mixed Valency; Molecular Wires and Switches. Chem. Soc. Rev. 1995, 24, 121-134. [CrossRef]

18. Inkpen, M.S.; Du, S.; Driver, M.; Albrecht, T.; Long, N.J. Oxidative Purification of Halogenated Ferrocenes, Dalton Trans. Dalton Trans 2013, 42, 2813-2816. [CrossRef] [PubMed]

19. Peng, H.; Cheng, L.; Luo, J.; Xu, K.; Sun, Q.; Dong, L.; Salhi, F.; Lee, P.P.S.; Chen, J.; Tang, B.Z. Simple Synthesis, Outstanding Thermal Stability, and Tunable Light-emitting and Optical-limiting Properties of Functional Hyperbranched Polyarylenes. Macromolecules 2002, 35, 5349-5351. [CrossRef]

20. Bao, Z.; Chen, Y.; Cai, R.; Yu, L. Conjugated Liquid-crystalline Polymers-Soluble and Fusible Poly(phenylethylene) by the Heck Coupling Reaction. Macromolecules 1993, 26, 5281-5286. [CrossRef]

21. SHELXTL v5.1; Bruker AXS: Madison, WI, USA, 1998.

22. Sheldrick, G.M. Crystal structure refinement with SHELXL. Acta Cryst. 2015, C71, 3-8.

(C) 2018 by the authors. Licensee MDPI, Basel, Switzerland. This article is an open access article distributed under the terms and conditions of the Creative Commons Attribution (CC BY) license (http:// creativecommons.org/licenses/by/4.0/). 